\title{
Signal transduction mechanisms involved in S100A4-induced activation of the transcription factor NF-KB
}

Ida Grotterød'1, Gunhild M Mælandsmo 1,2 and Kjetil Boye*1,3

\begin{abstract}
Background: The metastasis-promoting protein S100A4 activates the transcription factor NF-kB through the classical $\mathrm{NF}-\mathrm{kB}$ activation pathway. The upstream signal transduction mechanisms leading to increased NF-KB activity are, however, incompletely characterized.

Methods: The human osteosarcoma cell line II-11b was stimulated with recombinant S100A4 in the presence or absence of inhibitors of common signal transduction pathways, and NF-kB activity was examined using a luciferasebased reporter assay and phosphorylation of IKBa. mRNA expression was analyzed by real-time RT-PCR, protein expression was examined by Western blotting and IKK activity was measured using an in vitro kinase assay. The role of upstream kinases and the cell surface receptor RAGE was investigated by overexpression of dominant negative proteins and by siRNA transfection.

Results: The Ser/Thr kinase inhibitors H-7 and staurosporine inhibited S100A4-induced IkBa phosphorylation and subsequent NF-kB activation. The protein tyrosine kinase inhibitor genistein and the phospholipase $C$ inhibitor compound 48/80 had a partial inhibitory effect on IkBa phosphorylation, whereas inhibitors of protein kinase C, Gprotein coupled receptors and PI 3-kinases had no effect on the level of phosphorylation. Interestingly, S100A4 treatment induced activating phosphorylations of $\mathrm{IKKa} / \beta$, but neither $\mathrm{H}-7$ nor staurosporine was able to significantly inhibit IKK activation. Dominant negative MEKK1 or NIK did not inhibit S100A4-induced NF-KB activity, and S100A4 stimulation did not influence AKT phosphorylation. Furthermore, diminished expression of the putative S100 protein receptor RAGE did not affect the observed phosphorylation of IKBa.

Conclusions: S100A4 activates NF-kB by inducing phosphorylation of IKKa/ $\beta$, leading to increased IKBa phosphorylation. The Ser/Thr kinase inhibitors $\mathrm{H}-7$ and staurosporine attenuated S100A4-induced NF-KB activation and inhibited IKK-mediated phosphorylation of IKBa. S100A4-induced NF-KB activation was independent of the putative S100 protein receptor RAGE and the Ser/Thr kinases MEKK1, NIK and AKT. These findings lead to increased understanding of S100A4 signaling, which may contribute to the identification of novel targets for anti-metastatic therapy.
\end{abstract}

\section{Background}

The metastasis-promoting protein S100A4 belongs to the S100 family of structurally related calcium binding proteins $[1,2]$. The S100 proteins are expressed in a cell and tissue specific manner and are involved in a variety of cellular processes, such as cell cycle regulation, cell growth, differentiation and motility [3]. The protein level of

* Correspondence: kjetil.boye@rr-research.no

1 Department of Tumor Biology, Institute for Cancer Research, The Norwegian Radium Hospital, Oslo University Hospital, Montebello, 0310 Oslo, Norway

Full list of author information is available at the end of the article
S100A4 is elevated in several human cancers [1,2], and expression of the protein is correlated with poor prognosis in several malignancies, including breast and colorectal cancer [4,5]. Similar to other S100 proteins, S100A4 possesses both intracellular and extracellular functions. When applied extracellularly, S100A4 is able to promote metastasis, stimulate angiogenesis, induce cell motility and increase expression of matrix metalloproteinases [610]. Even though many of the biological effects are 
described, the mechanisms by which S100A4 exerts these effects are incompletely understood.

In a previous study we demonstrated increased NF- $\mathrm{KB}$ activity and phosphorylation of JNK (c-Jun N-terminal kinase) upon stimulation of II-11b cells with extracellular S100A4 [11]. S100A4-induced activation of NF-kB, ERK1/2 (extracellular signal-regulated kinase 1/2), p38 MAP kinase and JNK have also been demonstrated in other cell systems [6,10-13]. However, the connection between these kinases and NF- $\mathrm{KB}$ is not known, and the upstream mechanisms leading to S100A4-induced NF- $\mathrm{kB}$ activation have not been established. Receptor for Advanced Glycation End products (RAGE) has been suggested as a putative receptor for several S100 proteins [14]. RAGE-dependent activation of NF- $\mathrm{kB}$ and subsequent enhanced MMP-13 expression was observed in chondrocytes upon stimulation with S100A4 [10], but RAGE-independent effects have also been described [15]. Through interaction with annexin II S100A4 was able to induce angiogenesis [8], and in neurons heparan sulfate proteoglycans were necessary for S100A4-induced neurite extension [15]. Most likely, the protein also acts through so far unidentified mechanisms, and interaction with different receptors may explain the various biological effects of extracellular S100A4.

The heterodimeric transcription factor NF- $\mathrm{kB}$ is a central player in cancer development and progression. Schematically, NF- $\mathrm{KB}$ can be activated through either the classical or the alternative pathway. In the classical activation pathway NF- $\mathrm{KB}$ dimers are retained in the cytoplasm by binding a class of inhibitor proteins, called ІкBs. Upon activation, the IKK (IкB kinase) complex phosphorylates I $K B$ and thereby targets the latter for proteasome-mediated degradation. NF- $\mathrm{KB}$ dimers can then translocate to the nucleus where they bind DNA and regulate transcription [16].

Here, we demonstrate that extracellular S100A4 stimulates NF- $\kappa B$ activity by inducing phosphorylation of the IKK complex and subsequent IKK-mediated phosphorylation of IкB $\alpha$. The Ser/Thr kinase inhibitors H-7 and staurosporine reduced S100A4-induced IкB $\alpha$ phosphorylation and NF- $\mathrm{KB}$ activation, whereas inhibitors of other common signaling pathways had a minor or no effect. The Ser/Thr kinases MEKK1 (MEK Kinase 1), NIK (NF$\kappa \mathrm{B}$ Inducing Kinase) and AKT (protein kinase B), and the putative S100A4 receptor RAGE, were not involved in S100A4-induced NF-kB activation in the cell system investigated.

\section{Methods Materials}

Mouse recombinant His-S100A4 was produced as previously described by Haugen et al [17]. Suramin, U-73122, genistein, AG 18, H-7 and staurosporine were purchased from Calbiochem (Darmstadt, Germany), GDP $\beta$ (guanosine 5 '-[ $\beta$-thio]diphosphate trilithium salt), compound 48/80 and GF 109203X were obtained from Sigma-Aldrich (St. Louis, MO), and LY294002 was purchased from Cell Signaling Technology (Beverly, MA).

\section{Cell culture and treatment}

The human osteosarcoma cell lines KPDX, the in-house anti-S100A4 ribozyme transfected osteosarcoma cell line II-11b and its parent cell line OHS have been described previously [18-20]. The osteosarcoma cell line U2OS and the colorectal cancer cell lines HCT 116 and SW620 were obtained from ATCC (Rockville, MD). Cells were cultivated in RPMI-1640 (BioWhittaker, Verviers, Belgium) containing 8.5\% fetal bovine serum (FBS; Biochrome KG, Berlin, Germany), $20 \mathrm{mM}$ Hepes buffer (Lonza, Verviers, Belgium), and $2 \mathrm{mM}$ Glutamax (GIBCO BRL, Life Technologies, Paisley, UK). Human calvarial osteoblasts (lot number 3417) were obtained from ScienCell Research Laboratories (Carlsbad, CA) and cultivated in poly-Llysine coated flasks in Osteoblast Medium with Osteoblast Growth Supplement (ScienCell Research Laboratories, Carlsbad, CA). Subconfluent cultures were trypsinized and seeded at $6 \times 10^{4}$ cells $/ \mathrm{cm}^{2}$ unless otherwise stated. After overnight incubation, cell culture medium was replaced with fresh medium in the presence or absence of signal transduction inhibitors as indicated. The cells were further incubated for 30 minutes or one hour prior to addition of $2 \mu \mathrm{M} \mathrm{S100A4}$, and harvested at the indicated time points. Relevant solute controls were included in all experiments

\section{Western blot analysis}

Protein lysates were prepared as previously described [17]. Protease and phosphatase inhibitors were added to the lysis buffer just before use $(10 \mu \mathrm{g} / \mathrm{ml}$ each of leupeptin, pepstatin and aprotinin, $1 \mathrm{mM}$ PMSF, $5 \mathrm{mM} \mathrm{NaF}, 20$ $\mathrm{mM} \beta$-glycerophosphate and $0.5 \mathrm{mM}$ sodium orthovanadate). Western blotting was performed as described previously [21], with the exception that protein lysates were separated on 4-12\% NuPAGE Novex Bis-Tris Gels (Invitrogen, Carlsbad, CA) and that 5\% non-fat dry milk was used in the blocking solution (10\% for $\alpha$-tubulin). Primary antibodies were diluted in $5 \%$ non-fat dry milk or BSA in Tris-buffered saline (TBS) containing the below noted percentages of Tween 20. Anti-phospho-IкB $\alpha$ (Ser32/36; 1:2000; 0.05\% Tween 20; \#9246), anti IкB $\alpha$ (1:1000; 0.1\% Tween 20; \#9242), anti-phospho-IKK $\alpha / \beta$ (Ser176/180 for IKK $\alpha$ and Ser177/181 for IKK $\beta$; 1:1000; $0.1 \%$ Tween 20; \#2687) and anti-phospho-AKT (Ser473; 1:500; 0.1\% Tween 20; \#9271) were obtained from Cell Signaling Technology (Beverly, MA). Anti-RAGE (1:500; 0.05\% Tween 20; sc-80652) was obtained from Santa Cruz Biotechnology (Santa Cruz, CA), anti-IKK $\alpha$ (1:1000; 0.1\% 
Tween 20; AF3768) from R\&D systems (Minneapolis, $\mathrm{MN})$, and anti- $\alpha$-tubulin (1:1000; 0.25\% Tween 20; CP06) from Calbiochem (Darmstadt, Germany). Signals were visualized using Super Signal West Dura Extended Duration Substrate (Thermo Scientific, Waltham, MA). Scanning of exposed films were done by CanoScan 9900F (Canon, Oslo, Norway) and signals quantified by the KODAK MI v.4.0.1 software (Kodak, New Haven, CT).

\section{Transient transfection and plasmid constructs}

The NF- $\mathrm{kB}$ activity assay was performed as previously described [11]. Briefly, cells were transfected with NF-kB reporter plasmid using electroporation. After overnight incubation, cells were pretreated with inhibitors followed by incubation with $2 \mu \mathrm{M}$ S100A4 for one hour, harvested and the lysate assayed for luciferase activity using the Luciferase Assay System (Promega, Madison, WI). Kinase dead and wild type constructs of MEKK1 (MEKK1 KD and MEKK1 WT) [22] were purchased from Addgene (Addgene plasmid 12180 and 12181; Cambridge, MA), while NIK KD and WT were kind gifts from Dr. Jacques Piette (Laboratory of Virology and Immunology, University of Liege, Liege, Belgium). MEKK1 and NIK constructs were cotransfected with the NF- $\mathrm{kB}$ reporter using the same conditions as described previously [11].

\section{Real-time RT-PCR}

RNA isolation was performed using TRI Reagent ${ }^{\circ}$ (Ambion/Applied Biosystems, Foster City, CA). Reverse transcription and real-time PCR was performed as previously described [23]. $1 \mu \mathrm{g}$ total RNA was used for cDNA synthesis, and $1 / 20$ of the reaction mixture employed for each real-time RT-PCR reaction. YARS (tyrosyl-tRNA synthetase) was used as housekeeping gene. Primers used were as previously described $[11,24]$.

\section{Immunoprecipitation}

The IKK complex was immunoprecipitated from unstimulated cells and cells treated with $2 \mu \mathrm{M}$ S100A4 for the indicated time periods with or without $\mathrm{H}-7(30 \mu \mathrm{M})$ or staurosporine $(0.4 \mu \mathrm{M})$. Cells were harvested and cytoplasmic extracts isolated as described by Werner et al [25]. $200 \mu \mathrm{l}$ cytoplasmic extract was incubated with $1 \mu \mathrm{g}$ anti-IKKү (\#559675; BD Biosciences, Franklin Lakes, NJ) for 2 hours at $4^{\circ} \mathrm{C}$ and subsequently with Protein A agarose-conjugated beads (Amersham Biosciences, Uppsala, Sweden) for one hour at $4^{\circ} \mathrm{C}$. Beads were washed and collected on Costar Spin- $\mathrm{X}^{\circ}$ centrifuge tube filters (Corning Incorporated, Corning, NY). Proteins were eluted from the beads by adding warm sample buffer (100 mM Tris$\mathrm{HCl} \mathrm{pH} \mathrm{6.8,} \mathrm{15 \%} \mathrm{glycerol,} \mathrm{3 \%} \mathrm{SDS,} \mathrm{5 \%} \beta$-mercaptoethanol, $0.1 \%$ bromophenol blue and $10 \mathrm{mg} / \mathrm{ml}$ DTT), followed by incubation at $95^{\circ} \mathrm{C}$ for 1 minute and centrifugation at $13000 \mathrm{rpm}$ for 5 minutes. The immunoprecipitate was separated on $10 \% \mathrm{NuPAGE}^{\circ}$ Novex Bis-
Tris Gel (Invitrogen, Carlsbad, CA). After blotting the membranes were incubated with anti-phospho-IKK $\alpha / \beta$ and anti-IKK $\alpha$.

\section{IKK activity assay}

For IKK activity analyses, the IKK complex from unstimulated and S100A4-treated cells was immunoprecipitated as described above and the kinase reaction performed according to [25]. Briefly, beads containing precipitated IKK complex were incubated in $20 \mu$ l kinase buffer containing $20 \mu \mathrm{M}$ ATP (Fermentas, Vilnius, Lithuania), 10 $\mu \mathrm{Ci}$ [32P] ATP (Montebello Diagnostics, Oslo, Norway) and $0.5 \mu \mathrm{g}$ recombinant human IKB $\alpha$ (Cell Sciences, Canton, MA) for 30 minutes at $30^{\circ} \mathrm{C}$ with or without $\mathrm{H}-7$ (30 $\mu \mathrm{M})$ or staurosporine $(0.4 \mu \mathrm{M})$. The beads were pelleted by centrifugation, the reaction mixture was resolved on $10 \%$ NuPAGE ${ }^{\circ}$ Novex Bis-Tris Gels (Invitrogen, Carlsbad, $\mathrm{CA})$ and [32P] IкB $\alpha$ was detected by autoradiography. Proteins were eluted from the beads as described above, and the eluate loaded on $10 \%$ NuPAGE $^{\circ}$ Novex Bis-Tris Gels (Invitrogen, Carlsbad, CA), transferred to Immobilon-P membranes (Millipore, Bedford, MA) and immunoblotted using anti-IKK $\alpha$.

\section{siRNA transfection}

siRNA targeting RAGE was designed by use of the Rational siRNA Design software [26], with minor modifications: antisense: 5'-AACCAACUCUCUCCUGUAU-3', sense: 5'-AUACAGGAGAGAGUUGGUU-3'. Silencer Negative Control \#1 siRNA (Ambion/Applied Biosystems, Foster City, CA) was used as negative control. Lipofectamine (Invitrogen, Carlsbad, CA) was used in concentration of $2 \mu \mathrm{l} / \mathrm{ml}$ and cell transfection performed in Opti-MEM (Invitrogen, Carlsbad, CA) according to the manufacturer's procedure. Transfection mixtures contained $50 \mathrm{nM}$ siRNA and the complex was added to $10^{6}$ cells seeded in T-25 bottles using reverse transfection. After 24 hours incubation, fresh cell culture medium was added and the cells incubated further for 24 hours. Cells were then stimulated with $2 \mu \mathrm{M}$ S100A4 for one hour and harvested for protein isolation as described above.

\section{Statistical analysis}

All statistical analyses were performed using two-tailed Student's t-test. Cells treated with S100A4 and H-7/staurosporine were compared to S100A4-stimulated cells without inhibitor. P-values less than 0.05 were considered to be statistically significant.

\section{Results}

Signal transduction mechanisms involved in S100A4induced NF-KB activation and expression of target genes

We have previously reported that S100A4 stimulates NF$\mathrm{\kappa B}$ activity through the classical activation pathway in the II-11b cell line, by demonstrating increased phosphoryla- 
tion of $\operatorname{IkB} \alpha$ [11]. To investigate the upstream signal transduction mechanisms involved in S100A4-induced NF- $\mathrm{kB}$ activation, II-11b cells were treated with inhibitors of various signal transduction pathways: Ser/Thr kinases (H-7 and staurosporine), phospholipase C (U-73122 and compound 48/80), protein tyrosine kinases (AG 18 and genistein), protein kinase C (GF 109203X), G-protein coupled receptors (GDP $\beta$ and suramin) and phosphatidylinositol 3-kinases (PI 3-kinases; LY294002). The levels of phosphorylated I $\mathrm{K} \mathrm{B} \alpha$ were used to measure activity in the NF- $\mathrm{kB}$ pathway. The Ser/Thr kinase inhibitors H-7 and staurosporine reduced $I \kappa B \alpha$ phosphorylation levels in a dose dependent manner (Fig. 1A and 1B). A partial inhibitory effect was observed with genistein and compound $48 / 80$ at the highest concentrations, whereas no inhibition was observed with the other signal transduction inhibitors (Fig. 1C-J). Based on these initial experiments, H-7 and staurosporine were chosen for further studies. As previously shown [11], total $\mathrm{I} k \mathrm{~B} \alpha$ expression levels were reduced upon treatment with S100A4 (Fig. 2A and 2B; compare lanes 1 and 2). In S100A4-stimulated cells, increasing concentrations of $\mathrm{H}-7$ or staurosporine resulted in decreased levels of $\mathrm{I}_{\kappa} \mathrm{B} \alpha$ (Fig. $2 \mathrm{~A}$ and $2 \mathrm{~B}$; compare lanes 4, 6, 8 and 10 with lane 2). IкB $\alpha$ expression was also reduced in cells treated with staurosporine alone. Importantly, $\mathrm{H}-7$ and staurosporine displayed a potent and dose dependent inhibition of S100A4-induced NF-kB activation in a luciferase based activity assay, both using II-11b cells (Fig. 3A and 3B) and the human osteosarcoma cell line KPDX (Fig. 3C). Recently, we demonstrated that S100A4 augmented expression of ephrin-A1 and optineurin in II-11b cells, and that the induction was dependent on NF- $\mathrm{B}$ B activity [11]. Addition of H-7 or staurosporine suppressed S100A4-induced expression of these target genes in a dose dependent manner (Fig. 4). Taken together, these findings indicate that Ser/Thr kinases are central players in S100A4-induced NF-kB activation.

\section{S100A4 induces phosphorylation of IKKa/ $\beta$}

The IKK complex consists of the two catalytic subunits IKK $\alpha$ and IKK $\beta$ and the regulatory subunit IKK $\gamma /$ NEMO. In the classical NF- $\mathrm{B}$ activation pathway IKK $\alpha$ and IKK $\beta$ are activated by phosphorylation of specific serine residues in the activation loop, and is thereby able to induce serine phosphorylation of IkB $\alpha$ [27]. By immunoprecipitating the IKK complex from S100A4-stimulated II-11b cells, and subsequently subject the precipitate to immunoblotting using a phosphospecific IKK $\alpha / \beta$ antibody, a time dependent induction of $I K K \alpha / \beta$ phosphorylation was detected (Fig. 5A).

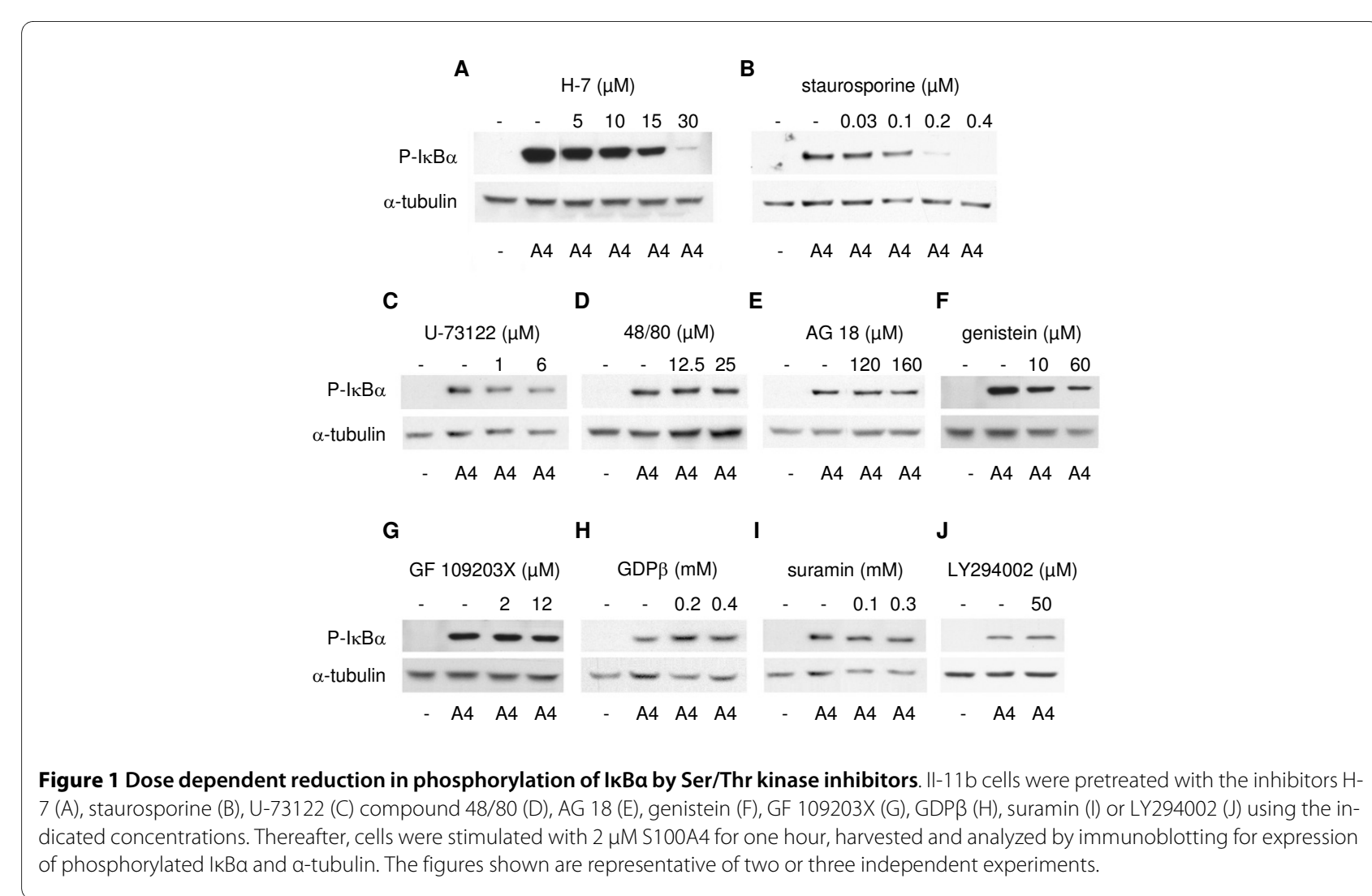




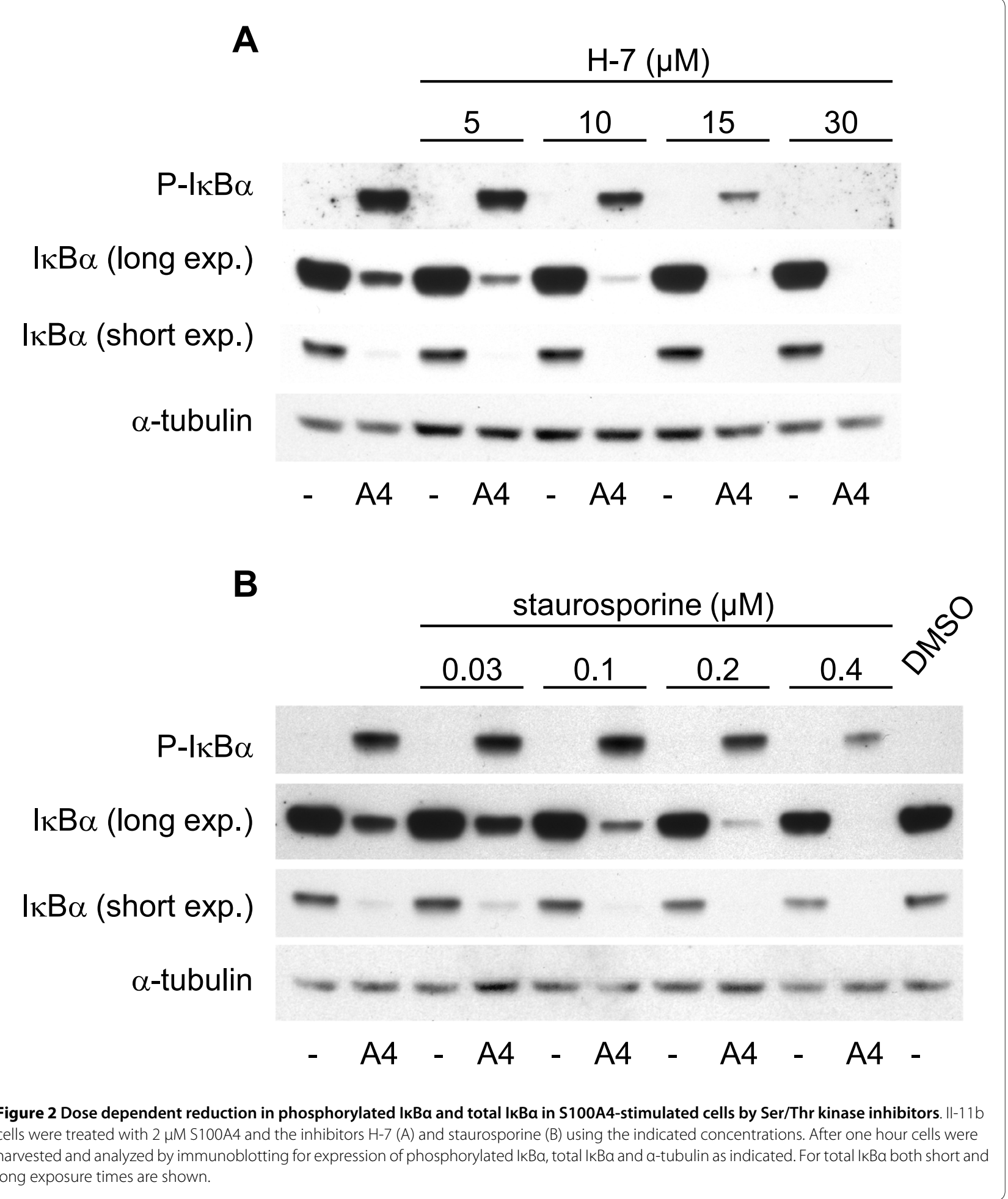

Inhibitors of Ser/Thr kinases suppress IKK-mediated phosphorylation of IKBa

The observed suppression of S100A4-induced IkB $\alpha$ phosphorylation and NF- $\mathrm{kB}$ activation by $\mathrm{H}-7$ and staurosporine could be caused by inhibition of several kinases in the activation pathway. Searching for involved kinases upstream of $\mathrm{I}_{\kappa} \mathrm{B} \alpha$, it was of interest to investigate whether $\mathrm{H}-7$ and staurosporine were able to inhibit IKK kinase activity or kinases upstream of IKK. In order to investigate this, the IKK complex was immunoprecipitated from untreated and S100A4-stimulated cells and incubated with recombinant $\mathrm{I} \kappa \mathrm{B} \alpha$ and radioactive ATP to measure 
A

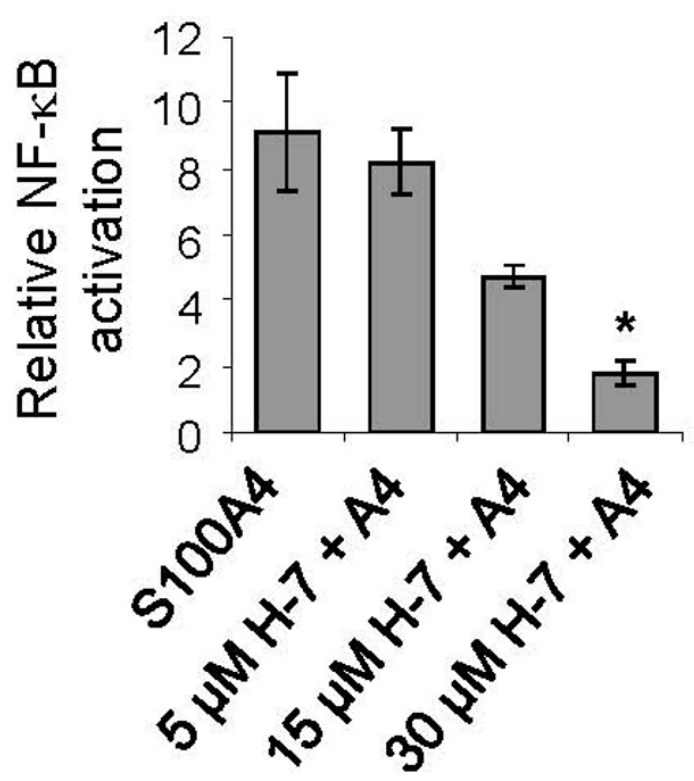

B

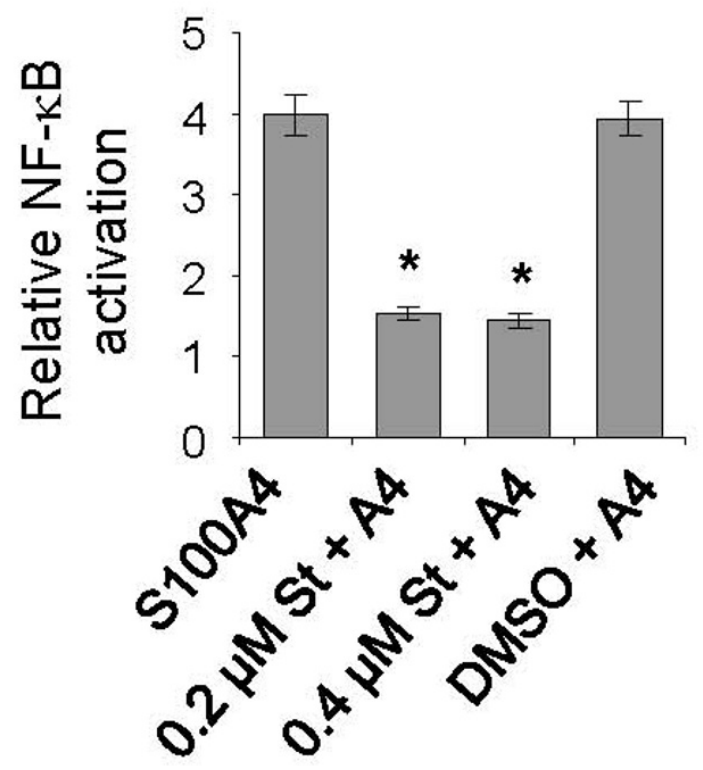

C

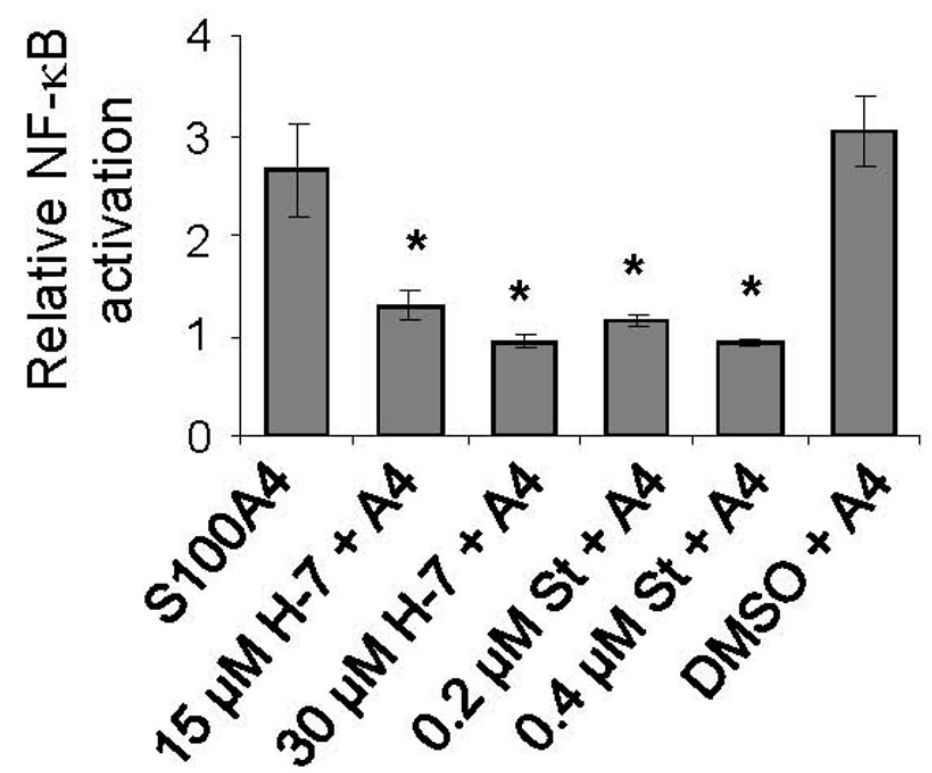

Figure 3 H-7 and staurosporine inhibit S100A4-induced NF-KB activity. II-11b (A and B) and KPDX (C) cells transfected with an NF-KB luciferase reporter construct were incubated with $\mathrm{H}-7$ or staurosporine prior to S100A4-stimulation. NF-KB activity is expressed as relative induction upon S100A4 treatment compared to relevant control. Bars represent mean values \pm S.E of three independent experiments performed in triplicate or duplicate. St = staurosporine. ${ }^{*}, p<0.05$ 


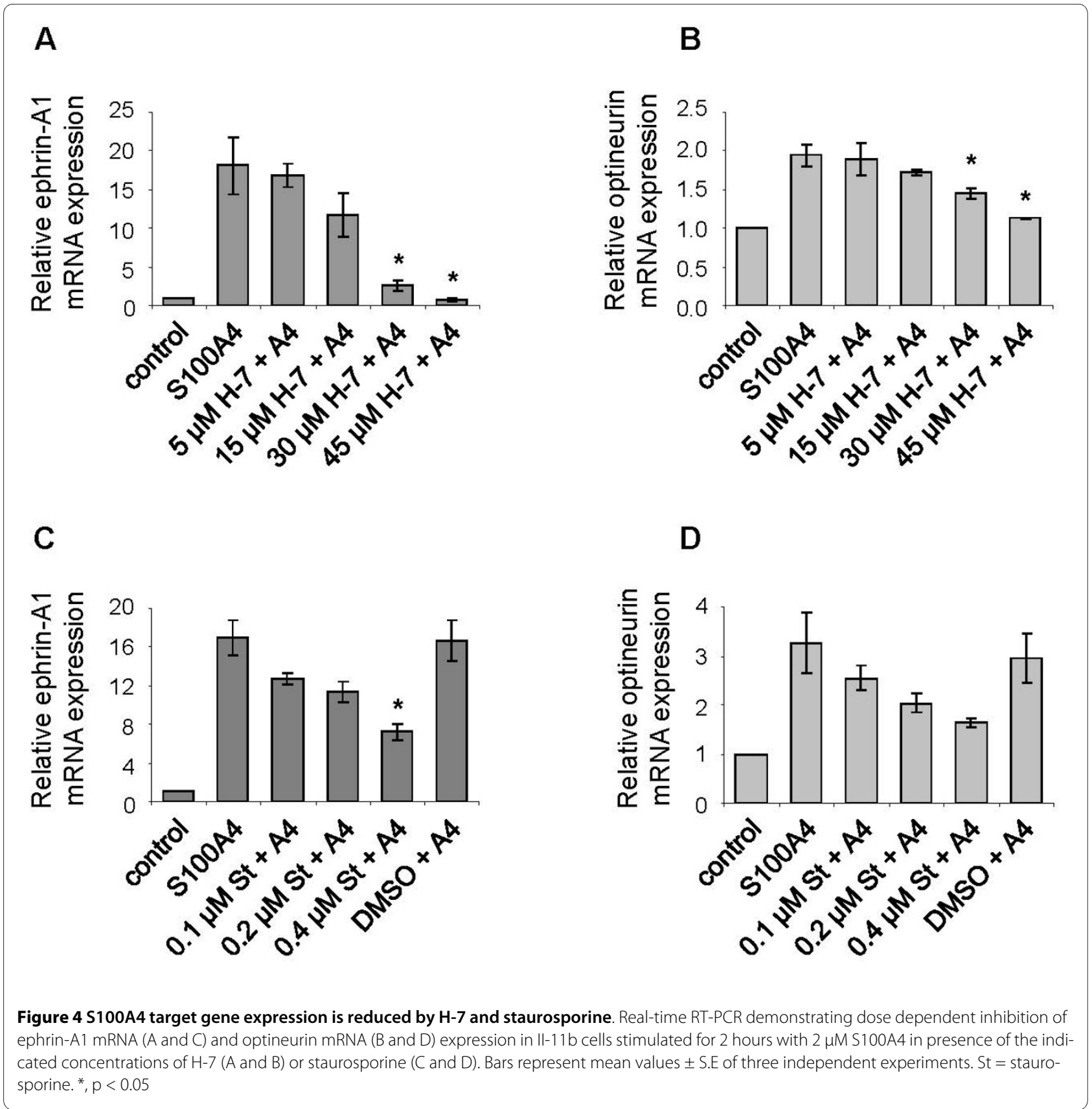

in vitro kinase activity. Fig. $5 \mathrm{~B}$ and $5 \mathrm{C}$ show that S100A4 treatment increased the ability of IKK to phosphorylate I $\mathrm{B} \alpha$ in vitro, while the presence of $\mathrm{H}-7$ or staurosporine reduced IKK-mediated IKB $\alpha$ phosphorylation. To examine whether $\mathrm{H}-7$ or staurosporine affected S100A4induced activation of the IKK complex, levels of phosphorylated $I K K \alpha / \beta$ were analyzed in untreated and S100A4-stimulated cells with or without H-7 or staurosporine added to the cell culture medium. A small reduction in phosphorylated $I K K \alpha / \beta$ was achieved in one of three experiments using staurosporine, whereas $\mathrm{H}-7$ did not suppress the phosphorylation levels (Fig. 5D and 5E).
Taken together these results indicate that neither $\mathrm{H}-7$ nor staurosporine inhibits S100A4-induced activation of the IKK complex, while both inhibitors are able to hinder IKK-mediated phosphorylation of IKB $\alpha$ in vitro.

\section{S100A4-induced NF-KB activation is independent of the} Ser/Thr kinases MEKK1, NIK and AKT

Previously, we demonstrated JNK phosphorylation after S100A4 treatment of II-11b cells [11]. MEKK1 is a possible common upstream kinase responsible for activating both the IKK complex and JNK [28]. It was therefore of interest to examine whether this kinase could be involved 


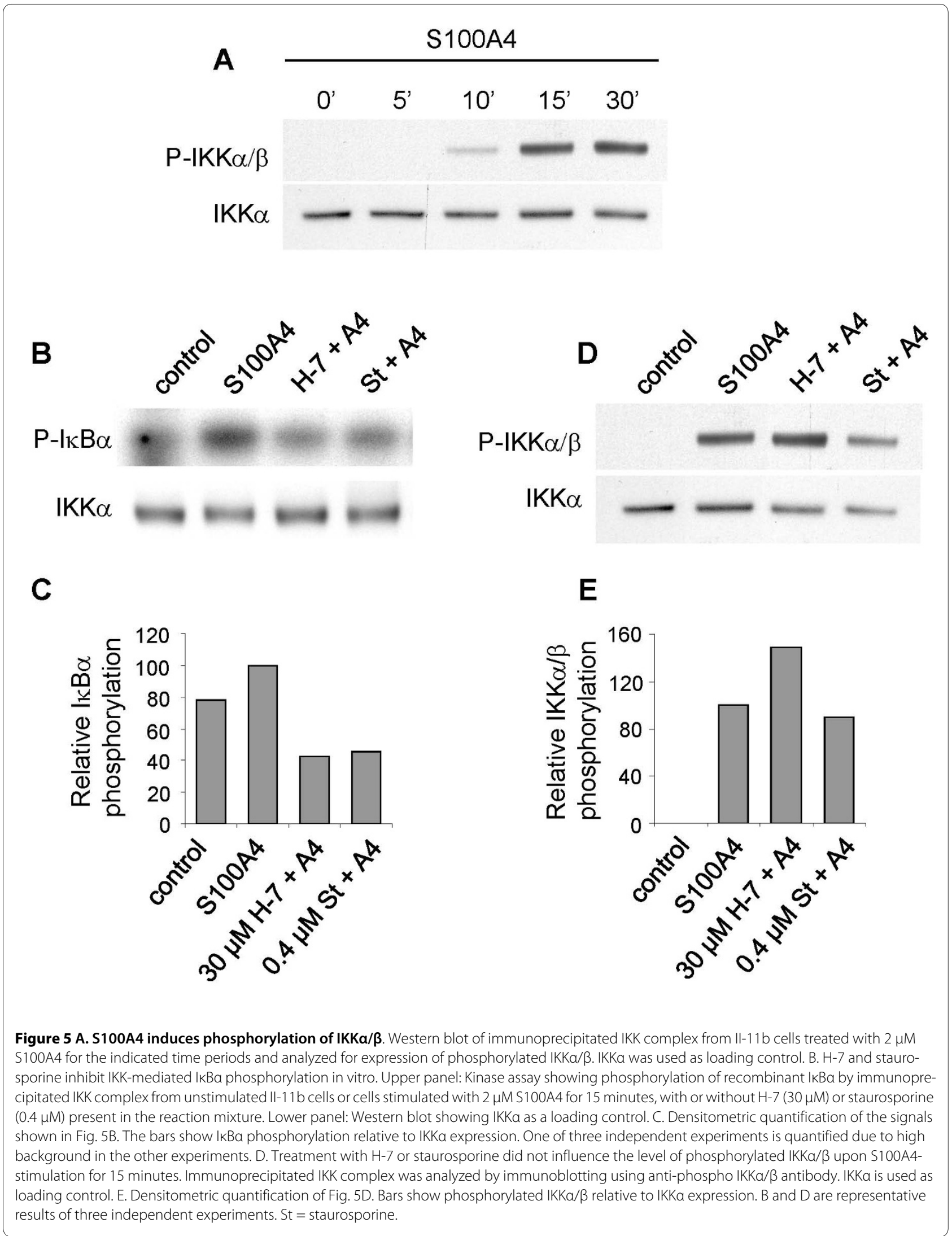


in S100A4-induced activation of NF-kB. However, no significant effect was observed on S100A4-induced IкB $\alpha$ phosphorylation or NF- $\mathrm{B}$ activation when dominant negative MEKK1 was overexpressed (Fig. 6A and 6B). It has also been shown that the Ser/Thr kinases NIK and AKT could be involved in phosphorylation and activation of the IKK complex [29,30]. As for MEKK1, dominant negative NIK was not able to inhibit S100A4-mediated $\mathrm{I} \kappa \mathrm{B} \alpha$ phosphorylation or NF- $\mathrm{B}$ activation (Fig. $6 \mathrm{~A}$ and $6 \mathrm{~B})$. Wild type MEKK1 and NIK was used in experiments to verify that the dominant negative constructs were able to suppress NF- $\mathrm{kB}$ activation induced by MEKK1 or NIK (Fig. 6C). Moreover, AKT phosphorylation at serine residue 473 was unaffected by treatment with S100A4 (Fig. 6D). AKT is normally phosphorylated after PI 3-kinase activation, and the finding that LY294002 had no effect on IkB $\alpha$ phosphorylation strengthens the conclusion that AKT is not involved in S100A4-induced IKK activation.

\section{S100A4-mediated NF-KB activation is RAGE-independent}

RAGE has been suggested as receptor for several S100 proteins. In an attempt to investigate the possible role of RAGE in S100A4-induced NF- $\mathrm{kB}$ signaling, siRNA molecules targeting RAGE mRNA were utilized. Fig. 7A shows that S100A4 induces phosphorylation of $I_{k} B \alpha$ to the same extent even with RAGE expression levels substantially reduced by siRNA transfection. Furthermore, RAGE expression in a panel of cell lines previously analyzed for NF- $\mathrm{kB}$ activation [11] was investigated, and no association between RAGE levels and S100A4-induced NF-kB activation was observed (Fig. 7B). Finally, S100A4-mediated phosphorylation of $I_{\kappa} \mathrm{B} \alpha$ was detected in human osteoblasts expressing low levels of RAGE (Fig. 7C). Altogether, these results indicate that RAGE is not involved in S100A4-induced NF- $\mathrm{kB}$ activation.

\section{Discussion}

S100A4-induced activation of the transcription factor $\mathrm{NF}-\mathrm{kB}$ has been reported in several cell systems $[6,10,13]$, but the mechanisms responsible for the enhanced activity are only partly elucidated. We have previously reported that S100A4 activates NF-kB through the classical activation pathway in the II-11b cell line [11], and the present study was initiated to reveal upstream signal transduction

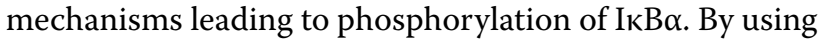
inhibitors of common signal transduction pathways, Ser/ Thr kinases were found to be essential for S100A4induced NF- $\mathrm{kB}$ activation. Inhibitors of phospholipase $\mathrm{C}$, protein tyrosine kinases, protein kinase $\mathrm{C}$, G-protein coupled receptors and PI 3-kinases had only a minor or no effect on I $\mathrm{B} \alpha$ phosphorylation in the examined osteosarcoma cell system. S100A4 was for the first time demonstrated to induce IKK $\alpha / \beta$ phosphorylation. The employed Ser/Thr kinase inhibitors $\mathrm{H}-7$ and staurosporine were able to inhibit the subsequent IKK-mediated phosphorylation of $\mathrm{I} \kappa \mathrm{B} \alpha, \mathrm{NF}-\kappa \mathrm{B}$ activation and expression of target genes, whereas the same inhibitors did not affect activation of the IKK complex. RAGE, previously suggested as a receptor for extracellular S100A4 and a well-known activator of NF- $\mathrm{kB}$ signaling, was not involved in S100A4induced NF- $\kappa$ B activation.

Both I $\mathrm{K} \mathrm{B} \alpha$ and subunits of the IKK complex are phosphorylated on serine residues. It was therefore of interest to examine whether IKK kinase activity or kinases upstream of IKK were suppressed by the added Ser/Thr kinase inhibitors. By utilizing immunoprecipitated IKK complex from S100A4-stimulated cells in an in vitro kinase assay, both inhibitors were demonstrated to reduce IKK-mediated phosphorylation of IKB $\alpha$. However, the phosphorylation status of the catalytic IKK subunits IKK $\alpha$ and IKK $\beta$ were not influenced. The molecular mechanisms of IKK activation have at present not been fully elucidated, but activity is known to depend on phosphorylation of serine residues in the activation loop of IKK $\alpha$ and IKK $\beta$ (as detected by the antibody utilized; Fig. $5)$. This may occur through direct phosphorylation by an upstream kinase, or by trans-autophosphorylation through induced proximity of IKK $\alpha / \beta$ as a result of IKK multimerization [27]. Because $\mathrm{H}-7$ and the broad spectrum kinase inhibitor staurosporine are able to inhibit IKK-mediated IKB $\alpha$ phosphorylation, one might expect that IKK autophosphorylation also would be suppressed by these inhibitors. In our experiments, IKK phosphorylation was not affected by $\mathrm{H}-7$ and staurosporine, suggesting that an upstream serine kinase could be responsible for the S100A4-mediated IKK $\alpha / \beta$ phosphorylation. In that event, there are at least three potential explanations for the lack of inhibition by $\mathrm{H}-7$ and staurosporine: (i) the upstream serine kinase is not inhibited by the Ser/Thr kinase inhibitors employed; (ii) the inhibitors were unable to significantly inhibit the upstream kinase at the concentrations and experimental conditions used in our experiments; and (iii) given that signaling components often are functionally redundant, alternative pathways could be activated, masking the inhibitory effect of the particular inhibitor added. Several kinases have been shown to participate in activation of the IKK complex, including the Ser/Thr kinases MEKK1, NIK and AKT [27-31]. Assuming that an upstream serine kinase is involved in S100A4-induced IKK activation, these candidates were further investigated. However, in the II-11b cell line no increase in AKT phosphorylation was observed upon stimulation with S100A4, and dominant negative NIK and MEKK1 had no effect on S100A4induced NF- $\mathrm{KB}$ activation.

The finding that total IkB $\alpha$ levels decreased in S100A4stimulated cells with increasing concentrations of $\mathrm{H}-7$ and staurosporine was somewhat surprising, and this 


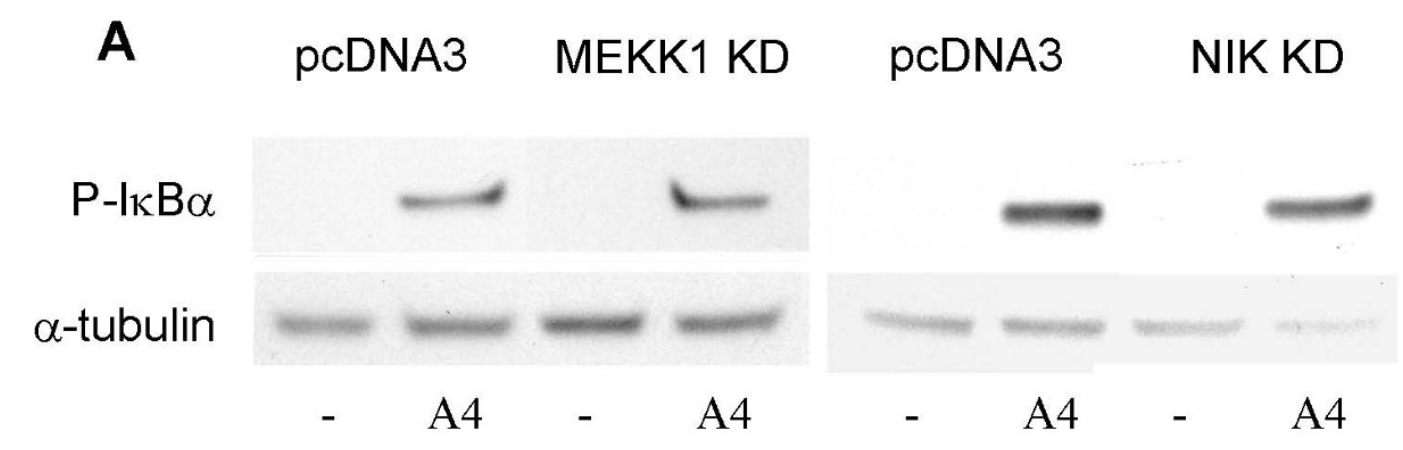

B

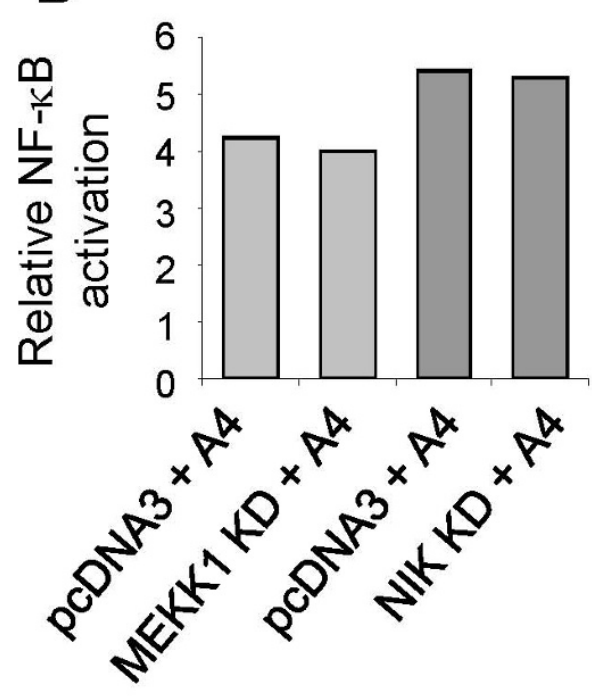

C

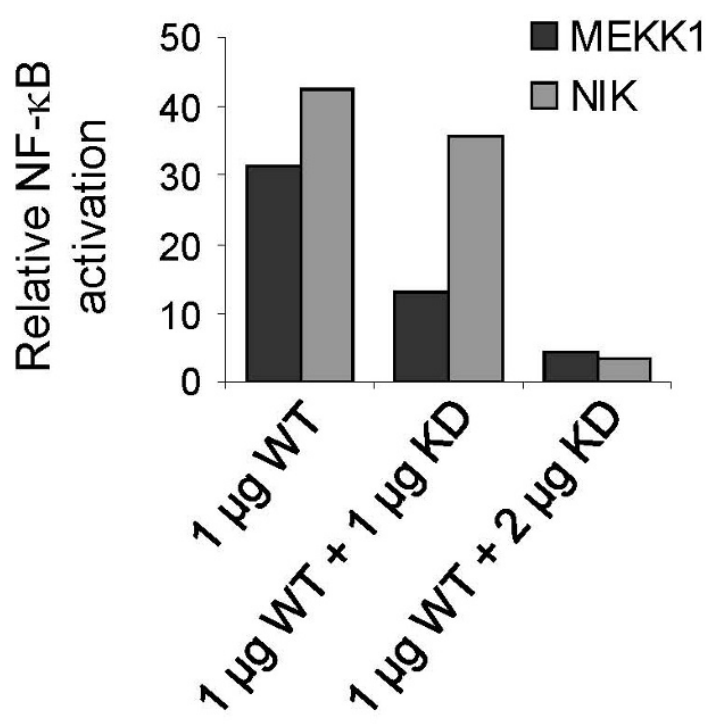

D

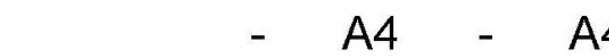

A4
15

30

P-AKT

- A4

- A4
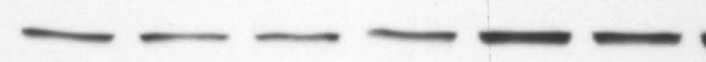

$\alpha$-tubulin

Figure 6 The Ser/Thr kinases MEKK1, NIK and AKT are not involved in S100A4-mediated activation of the IKK complex. A. Representative

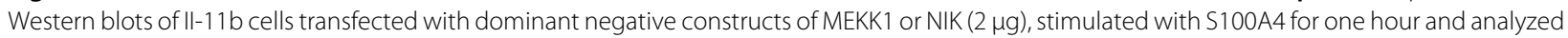
for expression of phosphorylated IKBa. B. Cotransfection of II-11 b cells with NF-KB luciferase reporter construct and dominant negative MEKK1 or NIK $(2 \mu \mathrm{g})$ as described in "Methods". Bars show relative induction of NF-KB activity upon S100A4 treatment compared to relevant control. KD = kinase dead. C. Control experiment to evaluate the ability of the dominant negative MEKK1 and NIK constructs to suppress NF-KB activity. Empty vector was used as transfection control and to adjust the amount of plasmid in each transfection. D. Western blot of II- $11 \mathrm{~b}$ cells treated with $2 \mu \mathrm{M} \mathrm{S100A4}$ for the indicated time periods, analyzed for levels of phosphorylated AKT and $\mathrm{a}$-tubulin. A, B and D are representative results of three independent experiments. 


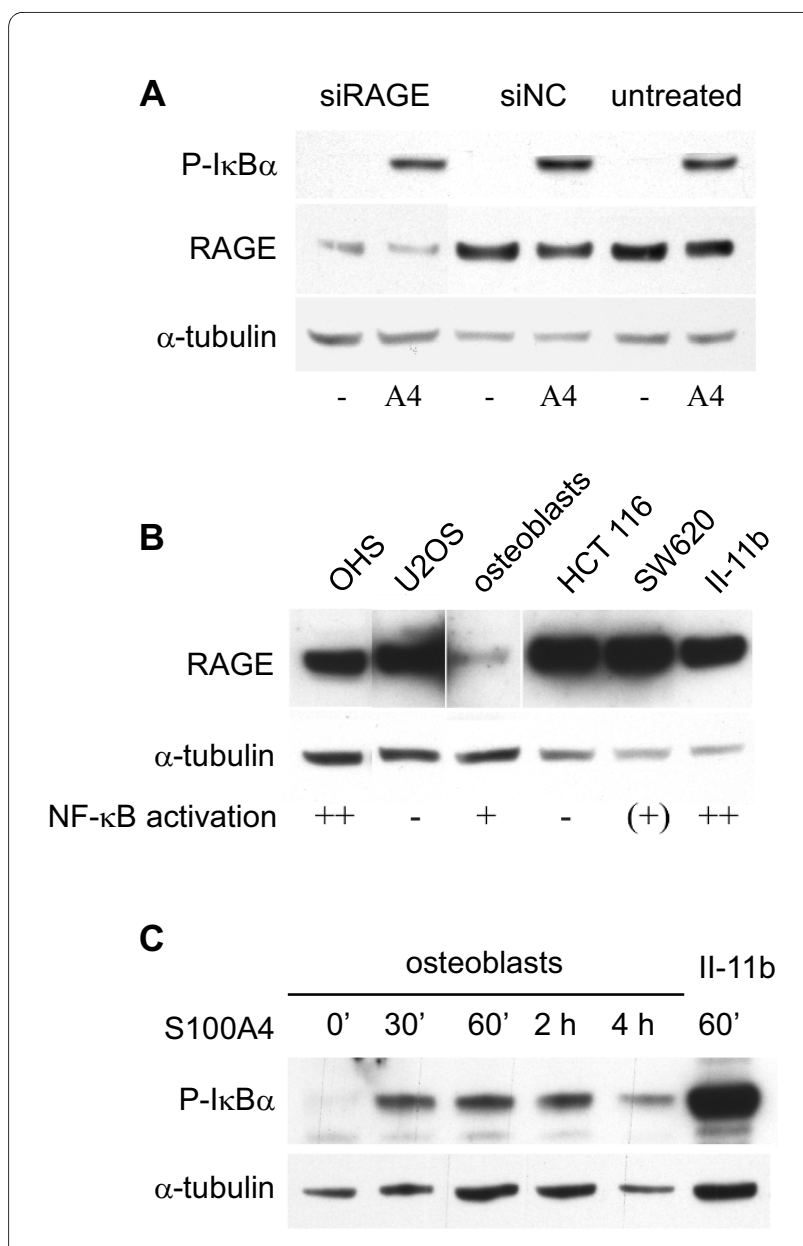

Figure 7 RAGE-independent NF-KB activation upon S100A4stimulation of II-11 b cells. A. Western blot showing reduced RAGE protein expression by siRNA transfection. 48 hours after transfection the cells were stimulated with S100A4 for one hour and cell lysates subjected to immunoblotting using anti-phospho-|KBa. The results shown are representative of three independent experiments. siNC = siRNA negative control. B. Western blot showing RAGE expression in a panel of cell lines. NF-KB activation refers to the levels of S100A4-induced NF-KB activation demonstrated in a previous study [11], except for osteoblasts, where it refers to $\mathrm{KB}$ a phosphorylation levels shown in Fig. 7C. C. Western blot showing IkBa phosphorylation in human osteoblasts after $\mathrm{S100A4}$ stimulation for the indicated time periods. a-tubulin was used as loading control.

observation may have at least two explanations. First, IкB $\alpha$ expression is reduced in cells treated with staurosporine alone, indicating that the mechanism is partly S100A4-independent. Second, NF-кB stimulates ІкB $\alpha$ transcription as part of a negative feedback mechanism, and the total level of IкB $\alpha$ thus represent the net result of protein degradation and resynthesis. In the II-11b cell line we have previously shown that S100A4-mediated NF- $\kappa B$ activation stimulates transcription of $I \kappa B \alpha$ [11]. Furthermore, the NF- $\mathrm{kB}$ transcription complex consists of several proteins, and multiple serine phosphorylations are required for optimal activation [32]. By affecting any of these phosphorylations $\mathrm{H}-7$ and staurosporine may inhibit NF- $\kappa B$ activation, and total I $\kappa \beta \alpha$ levels may as a consequence decrease upon treatment with S100A4 and the inhibitors compared to S100A4 alone. Nevertheless, the importance and biological relevance of S100A4induced IкB $\alpha$ phosphorylation is confirmed by previous data showing that S100A4-mediated NF- $\mathrm{KB}$ activation is dependent on ІкB $\alpha$ phosphorylation at Ser32/36 [11].

The protein tyrosine kinase inhibitor genistein and the phospholipase $C$ inhibitor compound 48/80 displayed a partial inhibition of S100A4-induced IKB $\alpha$ phosphorylation, but we were not able to confirm these results using other inhibitors of the same signaling pathways (AG 18 and U-73122, respectively). Furthermore, inhibitors of protein kinase C, G-protein coupled receptors and PI 3kinases were unable to affect S100A4-mediated IкB $\alpha$ phosphorylation. Except for PI 3-kinases, the above mentioned mediators have previously been reported involved in S100A4-induced signaling [10,12,15], and the seemingly conflicting results may be explained by cell line specific differences, for instance in expression of cell surface receptors or intracellular signal transduction molecules. As discussed above, functional redundancy may also explain the divergent results.

The effect of S100A4 on IKK phosphorylation was detected as early as after 10 minutes, indicating receptormediated transduction of the signal from the extracellular environment to intracellular effector molecules. Many S100 proteins have been found to transduce their effects through RAGE, but RAGE-independent effects have been observed both for S100A4 and other S100 proteins [14]. NF- $k B$ activation is a well-known downstream event of RAGE signaling, and NF- $\mathrm{kB}$ activation by S100A4 [10], S100A1 [33], S100A8/A9 [34], S100A12 [35], S100B [33] and S100P [36] has been shown to be RAGE-dependent in certain cell systems. Therefore, we examined the involvement of RAGE in S100A4-induced NF- $k B$ activation in II-11b cells. Using siRNA molecules targeting RAGE mRNA, expression was substantially reduced without observing any effect on S100A4-stimulated I $\mathrm{B} \alpha \alpha$ phosphorylation. The exact protein expression levels of RAGE necessary to maintain downstream signal transduction is not known, but the observed reduction in RAGE expression was more pronounced than in other studies demonstrating RAGE-dependent effects [34], suggesting that the observed S100A4-mediated activation of NF-kB is RAGE-independent. Accordingly, S100A4induced neurite outgrowth occurs through RAGE-independent mechanisms [15], and extracellular S100A4 stimulates motility and activates NF- $\mathrm{kB}$ in cells that do not express RAGE mRNA [6,7]. 
Signaling through RAGE is clearly responsible for biological effects induced by extracellular S100A4 in certain cell systems, but other cell surface molecules have also been suggested to be involved in S100A4 signaling. Neurite outgrowth mediated by S100A4 was partly dependent on interaction with heparan sulfate proteoglycans at the cell surface [15], and other S100 proteins also bind heparan sulfate moieties [37]. In the II-11b cell line treatment with heparin had no effect on S100A4-induced NF-kB activation (results not shown), indicating that S100A4induced NF- $\mathrm{kB}$ signaling is not dependent on interaction with glycosaminoglycans at the cell surface. On endothelial cells, S100A4 interacts with annexin II, which acts as a coreceptor governing the assembly of S100A4, plasminogen and its activators [8]. However, annexin II is not known to propagate intracellular signals upon binding to S100A4. Altogether, our findings suggest that a so far unidentified cell surface receptor mediates S100A4induced NF-kB activation.

\section{Conclusions}

Extracellular signals enhancing tumor cells metastatic capacity might be attractive candidates for therapeutic intervention. One such candidate is the metastasis-promoting protein S100A4. In the present study we used a human osteosarcoma cell line to demonstrate that extracellular S100A4 activates the IKK complex and induces NF- $\kappa B$ activity independent of the postulated S100 receptor RAGE. Further studies to identify possible S100A4 specific receptor molecule(s) and induced downstream signaling pathway(s) may identify targets that can be utilized in anti-metastatic therapy.

\section{Competing interests}

The authors declare that they have no competing interests.

\section{Authors' contributions}

IG carried out all the laboratory experiments and drafted the manuscript. GMM and $\mathrm{KB}$ conceived and designed the study. All authors read and approved the final manuscript.

\section{Acknowledgements \\ We gratefully acknowledge Dr. Jacques Piette (Laboratory of Virology and Immunology, University of Liege, Liege, Belgium) for providing the NIK expres- sion constructs and Dr. Gary L Johnson (The National Jewish Medical and Research Center, Denver, CO) for providing the MEKK1 constructs. The authors would like to thank Tove Øyjord for excellent technical assistance. This work was supported by the Norwegian Cancer Society (C99026 to IG and GMM) and The National Program for Research in Functional Genomics of the Research Council of Norway (158954/S10 to GMM).}

\section{Author Details}

1Department of Tumor Biology, Institute for Cancer Research, The Norwegian Radium Hospital, Oslo University Hospital, Montebello, 0310 Oslo, Norway, 2Department of Pharmacy, Faculty of Health Sciences, University of Tromsø, 9037 Tromsø, Norway and ${ }^{3}$ Department of Oncology, The Norwegian Radium Hospital, Oslo University Hospital, Montebello, 0310 Oslo, Norway
References

1. Garrett SC, Varney KM, Weber DJ, Bresnick AR: S100A4, a mediator of metastasis. J Biol Chem 2006, 281:677-680.

2. Boye K, Maelandsmo GM: S100A4 and metastasis: a small actor playing many roles. Am J Pathol 2010, 176:528-535.

3. Marenholz I, Heizmann CW, Fritz G: S100 proteins in mouse and man: from evolution to function and pathology (including an update of the nomenclature). Biochem Biophys Res Commun 2004, 322:1111-1122.

4. Rudland PS, Platt-Higgins A, Renshaw C, West CR, Winstanley JH, Robertson L, Barraclough R: Prognostic significance of the metastasisinducing protein S100A4 (p9Ka) in human breast cancer. Cancer Res 2000, 60:1595-1603

5. Gongoll S, Peters G, Mengel M, Piso P, Klempnauer J, Kreipe H, von Wasielewski R: Prognostic significance of calcium-binding protein S100A4 in colorectal cancer. Gastroenterology 2002, 123:1478-1484.

6. Schmidt-Hansen B, Ornas D, Grigorian M, Klingelhofer J, Tulchinsky E, Lukanidin E, Ambartsumian N: Extracellular S100A4(mts1) stimulates invasive growth of mouse endothelial cells and modulates MMP-13 matrix metalloproteinase activity. Oncogene 2004, 23:5487-5495.

7. Belot N, Pochet R, Heizmann CW, Kiss R, Decaestecker C: Extracellular S100A4 stimulates the migration rate of astrocytic tumor cells by modifying the organization of their actin cytoskeleton. Biochim Biophys Acta 2002, 1600:74-83.

8. Semov A, Moreno MJ, Onichtchenko A, Abulrob A, Ball M, Ekiel I, Pietrzynski G, Stanimirovic D, Alakhov V: Metastasis-associated protein S100A4 induces angiogenesis through interaction with Annexin II and accelerated plasmin formation. J Biol Chem 2005, 280:20833-20841.

9. Schmidt-Hansen B, Klingelhofer J, Grum-Schwensen B, Christensen A, Andresen S, Kruse C, Hansen T, Ambartsumian N, Lukanidin E, Grigorian M: Functional significance of metastasis-inducing S100A4(Mts1) in tumorstroma interplay. J Biol Chem 2004, 279:24498-24504.

10. Yammani RR, Carlson CS, Bresnick AR, Loeser RF: Increase in production of matrix metalloproteinase 13 by human articular chondrocytes due to stimulation with S100A4: Role of the receptor for advanced glycation end products. Arthritis Rheum 2006, 54:2901-2911.

11. Boye K, Grotterod I, Aasheim HC, Hovig E, Maelandsmo GM: Activation of NF-kappaB by extracellular S100A4: analysis of signal transduction mechanisms and identification of target genes. Int J Cancer 2008, 123:1301-1310.

12. Novitskaya V, Grigorian M, Kriajevska M, Tarabykina S, Bronstein I, Berezin $V$, Bock E, Lukanidin E: Oligomeric forms of the metastasis-related Mts 1 (S100A4) protein stimulate neuronal differentiation in cultures of rat hippocampal neurons. J Biol Chem 2000, 275:41278-41286.

13. Hsieh HL, Schafer BW, Weigle B, Heizmann CW: S100 protein translocation in response to extracellular $\mathrm{S} 100$ is mediated by receptor for advanced glycation endproducts in human endothelial cells. Biochem Biophys Res Commun 2004, 316:949-959.

14. Donato R: RAGE: a single receptor for several ligands and different cellular responses: the case of certain S100 proteins. Curr Mol Med 2007, 7:711-724.

15. Kiryushko D, Novitskaya V, Soroka V, Klingelhofer J, Lukanidin E, Berezin V, Bock E: Molecular mechanisms of $\mathrm{Ca}(2+)$ signaling in neurons induced by the S100A4 protein. Mol Cell Biol 2006, 26:3625-3638.

16. Karin M: Nuclear factor-kappaB in cancer development and progression. Nature 2006, 441:431-436.

17. Haugen MH, Flatmark K, Mikalsen SO, Malandsmo GM: The metastasisassociated protein $\mathrm{S100A4}$ exists in several charged variants suggesting the presence of posttranslational modifications. $B M C$ Cancer 2008, 8:172.

18. Maelandsmo GM, Hovig E, Skrede M, Engebraaten O, Florenes VA Myklebost O, Grigorian M, Lukanidin E, Scanlon KJ, Fodstad O: Reversal of the in vivo metastatic phenotype of human tumor cells by an antiCAPL (mts1) ribozyme. Cancer Res 1996, 56:5490-5498.

19. Fodstad O, Brogger A, Bruland O, Solheim OP, Nesland JM, Pihl A: Characteristics of a cell line established from a patient with multiple osteosarcoma, appearing 13 years after treatment for bilateral retinoblastoma. Int J Cancer 1986, 38:33-40.

20. Bruland O, Fodstad O, Pihl A: The use of multicellular spheroids in establishing human sarcoma cell lines in vitro. Int J Cancer 1985, 35:793-798 
21. Pedersen KB, Andersen K, Fodstad O, Maelandsmo GM: Sensitization of interferon-gamma induced apoptosis in human osteosarcoma cells by extracellular S100A4. BMC Cancer 2004, 4:52.

22. Widmann C, Gerwins P, Johnson NL, Jarpe MB, Johnson GL: MEK kinase 1, a substrate for DEVD-directed caspases, is involved in genotoxininduced apoptosis. Mol Cell Biol 1998, 18:2416-2429.

23. Lillehammer T, Tveito S, Engesaeter BO, Fodstad O, Maelandsmo GM, Engebraaten O: Melanoma-specific expression in first-generation adenoviral vectors in vitro and in vivo -- use of the human tyrosinase promoter with human enhancers. Cancer Gene Ther 2005, 12:864-872.

24. Boye K, Andersen K, Tveito S, Oyjord T, Maelandsmo GM: Interferongamma-induced suppression of $\mathrm{S100A4}$ transcription is mediated by the class II transactivator. Tumour Biol 2007, 28:27-35.

25. Werner SL, Barken D, Hoffmann A: Stimulus specificity of gene expression programs determined by temporal control of IKK activity. Science 2005, 309:1857-1861.

26. Reynolds A, Leake D, Boese Q, Scaringe S, Marshall WS, Khvorova A: Rational siRNA design for RNA interference. Nat Biotechnol 2004, 22:326-330

27. Hacker H, Karin M: Regulation and function of IKK and IKK-related kinases. SCi STKE 2006, 2006:re13.

28. Lee FS, Hagler J, Chen ZJ, Maniatis T: Activation of the IkappaB alpha kinase complex by MEKK1, a kinase of the JNK pathway. Cell 1997, 88:213-222.

29. Rangaswami H, Bulbule A, Kundu GC: Nuclear factor inducing kinase: a key regulator in osteopontin- induced MAPK/lkappaB kinase dependent NF-kappaB-mediated promatrix metalloproteinase-9 activation. Glycoconj J 2006, 23:221-232.

30. Das R, Philip S, Mahabeleshwar GH, Bulbule A, Kundu GC: Osteopontin: it's role in regulation of cell motility and nuclear factor kappa Bmediated urokinase type plasminogen activator expression. IUBMB Life 2005, 57:441-447.

31. Chen F, Demers LM, Shi X: Upstream signal transduction of NF-kappaB activation. Curr Drug Targets Inflamm Allergy 2002, 1:137-149.

32. Viatour P, Merville MP, Bours V, Chariot A: Phosphorylation of NF-kappaB and IkappaB proteins: implications in cancer and inflammation. Trends Biochem Sci 2005, 30:43-52.

33. Huttunen HJ, Kuja-Panula J, Sorci G, Agneletti AL, Donato R, Rauvala H: Coregulation of neurite outgrowth and cell survival by amphoterin and S100 proteins through receptor for advanced glycation end products (RAGE) activation. J Biol Chem 2000, 275:40096-40105.

34. Ghavami S, Rashedi I, Dattilo BM, Eshraghi M, Chazin WJ, Hashemi M, Wesselborg S, Kerkhoff C, Los M: S100A8/A9 at low concentration promotes tumor cell growth via RAGE ligation and MAP kinasedependent pathway. J Leukoc Biol 2008, 83:1484-1492.

35. Hofmann MA, Drury S, Fu C, Qu W, Taguchi A, Lu Y, Avila C, Kambham N, Bierhaus A, Nawroth P, et al:: RAGE mediates a novel proinflammatory axis: a central cell surface receptor for $\mathrm{S100/calgranulin} \mathrm{polypeptides.}$ Cell 1999, 97:889-901.

36. Arumugam T, Simeone DM, Schmidt AM, Logsdon CD: S100P stimulates cell proliferation and survival via receptor for activated glycation end products (RAGE). J Biol Chem 2004, 279:5059-5065.

37. Robinson MJ, Tessier P, Poulsom R, Hogg N: The S100 family heterodimer, MRP-8/14, binds with high affinity to heparin and heparan sulfate glycosaminoglycans on endothelial cells. J Biol Chem 2002, 277:3658-3665.

Pre-publication history

The pre-publication history for this paper can be accessed here: http://www.biomedcentral.com/1471-2407/10/241/prepub

doi: 10.1186/1471-2407-10-241

Cite this article as: Grotterød et al., Signal transduction mechanism involved in S100A4-induced activation of the transcription factor NF-?B BMC Cancer 2010, 10:241

\section{Submit your next manuscript to BioMed Central} and take full advantage of:

- Convenient online submission

- Thorough peer review

- No space constraints or color figure charges

- Immediate publication on acceptance

- Inclusion in PubMed, CAS, Scopus and Google Scholar

- Research which is freely available for redistribution

Submit your manuscript at www.biomedcentral.com/submit
C Biomed Central 